\title{
Synthesis and Biological Evaluation of Some Novel Dithiocarbamate Derivatives
}

\author{
Begüm Nurpelin Sağlık, ${ }^{1}$ Yusuf Özkay, ${ }^{1}$ Ümide Demir Özkay, ${ }^{2}$ and Hülya Karaca Gençer ${ }^{3}$ \\ ${ }^{1}$ Department of Pharmaceutical Chemistry, Faculty of Pharmacy, Anadolu University, 26470 Eskişehir, Turkey \\ ${ }^{2}$ Department of Pharmacology, Faculty of Pharmacy, Anadolu University, 26470 Eskişehir, Turkey \\ ${ }^{3}$ Department of Pharmaceutical Microbiology, Faculty of Pharmacy, Anadolu University, 26470 Eskişehir, Turkey
}

Correspondence should be addressed to Yusuf Özkay; yozkay70@gmail.com

Received 29 July 2014; Accepted 9 September 2014; Published 13 October 2014

Academic Editor: Xinyong Liu

Copyright (c) 2014 Begüm Nurpelin Sağlık et al. This is an open access article distributed under the Creative Commons Attribution License, which permits unrestricted use, distribution, and reproduction in any medium, provided the original work is properly cited.

\begin{abstract}
18 novel dithiocarbamate derivatives were synthesized in order to investigate their inhibitory potency on acetylcholinesterase enzyme and antimicrobial activity. Structures of the synthesized compounds were elucidated by spectral data and elemental analyses. The synthesized compounds showed low enzyme inhibitory activity. However, they displayed good antimicrobial activity profile. Antibacterial activity of compounds $4 \mathbf{a}, 4 \mathbf{e}$, and $\mathbf{4 p}(\mathrm{MIC}=25 \mu \mathrm{g} / \mathrm{mL})$ was equal to that of chloramphenicol against Klebsiella pneumoniae (ATCC 700603) and Escherichia coli (ATCC 35218). Most of the compounds exhibited notable antifungal activity against Candida albicans (ATCC 10231), Candida glabrata (ATCC 90030), Candida krusei (ATCC 6258), and Candida parapsilosis (ATCC 7330). Moreover, compound 4a, which carries piperidin-1-yl substituent and dimethylthiocarbamoyl side chain as variable group, showed twofold better anticandidal effect against all Candida species than reference drug ketoconazole.
\end{abstract}

\section{Introduction}

Alzheimer's disease (AD) is a an age associated neurodegenerative syndrome with clinical characteristic and pathological properties as loss of neurons in certain brain regions leading to deficiency of memory, cognitive dysfunction, behavioral disturbances, and deficits in activities of daily living, which eventually leads to death [1-3]. Although the underlying pathophysiological mechanisms are not clear, AD is firmly associated with impairment in cholinergic pathway, which results in reduced level of acetylcholine (Ach) that is hydrolysed by cholinesterases (ChE) in certain areas of brain $[1,2,4$, 5]. It is well known that there are two major forms of ChE in the brain of mammals. These are acetylcholinesterase (AChE) and butyrylcholinesterase (BuChE) found in neurons and glial cells and in neuritic plaques and tangles in Alzheimer's disease $(\mathrm{AD})$ patients [6].

Since the late 1970s the treatment of AD has proceeded and trended to a transmitter replacement strategy. Elevation of acetylcholine levels in brain through the use of $\mathrm{AChE}$ inhibitors has been established as the most effective treatment strategy against AD [3, 7]. Therefore, AChE and/or $\mathrm{BuChE}$ inhibitors have been recognised as the drug of choice in management of AD [8]. Several AChE inhibitors called as "cognitive enhancers" are being investigated for the symptomatic treatment of Alzheimer's disease $[2,7,8]$. These drugs increase the concentration of acetylcholine at the neurotransmitter sites or acts by regulating activity at nicotinic receptors $[2,4]$.

There are three important subsites in ChE; anionic site, oxyanion hole, and acyl pocket [9]. Carbamates as pyridostigmine, rivastigmine, and physostigmine constitute a class of ChE inhibitors. These compounds have been reported to direct their carbamate region towards the acyl pocket that includes esteratic site of the enzyme. This inhibition is subsequently reversed upon decarbamylation (Figure 1). However, carbamates have a relatively short duration of action and limited penetration to blood-brain barrier [10]. 


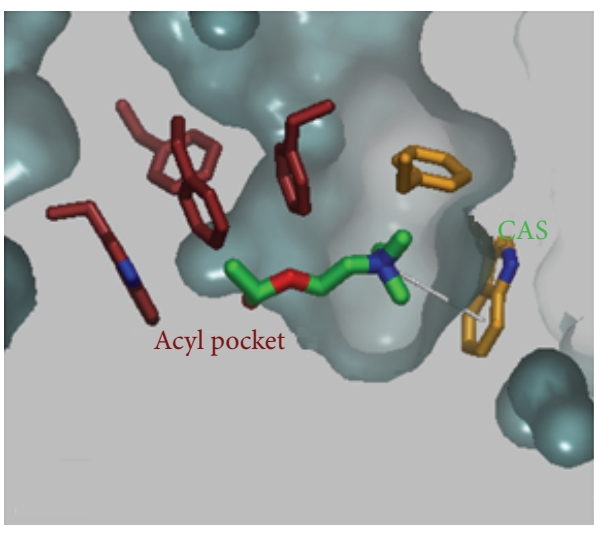

(a)

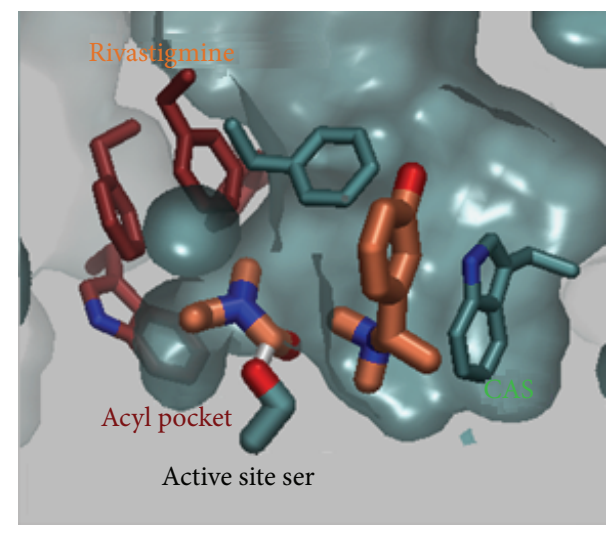

(b)

FIGURE 1: (a) Ligand binding sites in acetylcholinesterase. Hydrophobic residues in the gorge are shown as orange sticks. The surface of the protein is shown in cadetblue. Acetylcholine (green sticks) is shown in the catalytic anionic site (CAS). $\pi$-Cation interactions and hydrogen bonds are shown as white dotted lines. The acyl pocket residues are shown as brown sticks. (b) Interaction between rivastigmine and acetylcholinesterase. After hydrolysis, rivastigmine, shown as coral sticks, releases the carbamate residue towards the acyl pocket and enzyme inhibition occurs. Images were taken from the official web site of European Bioinformatics Institute.

Dithiocarbamates have attracted a great deal of interest in medicinal chemistry due to the fact that new effective compounds can be gained by the bioisosteric replacement of carbamate moiety with dithiocarbamate moiety. They are also important pharmacophores because of their lipophilicity, which is essential for the delivery of central nervous system (CNS) drugs to their site of action through the blood-brain barrier [11-18]. Thus, evaluation of novel dithiocarbamate derivatives as potential AChE inhibitors will be rational.

The treatment of infectious diseases still remains a crucial problem because of the increasing number of multidrug resistant microbial pathogens. In spite of a large number of antibiotics and chemotherapeutics existing for therapeutic use, the emergence of antibiotic resistance developed in the last decades has created a substantial medical need for new classes of antibacterial agents. A potential approach to overcome the resistance problem is to design novel agents with a different mode of action [19, 20].

In addition to their potential AChE inhibitory activity, dithiocarbamate derivatives are important compounds in antimicrobial chemotherapy due to their antibacterial and antifungal properties. First, Miller and Elson [21] and Kligman and Rosensweig [22] determined the activity of dimethyl dithiocarbamate salts against several pathogenic fungi and commented on their possible application in human therapy. In the last decade, dithiocarbamate moiety combined heterocyclic ring systems were studied widely, and now these compounds form a promising group of novel antifungal agents [23].

Cyclic amines as piperidine, piperazine, and morpholine possess antimicrobial importance and thus they are often subjected to new antimicrobial agents development studies. For instance, quinoline drugs as norfloxacin and ciprofloxacin carry piperazine nucleus and show broad antibacterial activity spectrum [24]. Linezolid, used for the treatment of infections caused by gram-positive bacteria, includes morpholine group [25-27]. Piperidine based chemical entities with aryl substituents have been documented as potent microbial agents [28, 29].

On the basis of above findings, in the present study we report the synthesis and biological evaluation of some novel dithiocarbamate derivatives as probable anticholinesterase and antimicrobial agents.

\section{Experiment}

2.1. Materials. All reagents were purchased from commercial suppliers and were used without further purification. Melting points were determined on an Electrothermal 9100 melting point apparatus (Weiss-Gallenkamp, Loughborough, UK) and were uncorrected. IR spectra were recorded on Shimadzu 8400 FT-IR spectrophotometer (Shimadzu, Tokyo, Japan). ${ }^{1} \mathrm{H}$-NMR spectra were recorded on a Bruker $500 \mathrm{MHz}$ spectrometer (Bruker, Billerica, USA). Mass spectra were recorded on a VG Quattro mass spectrometer (Agilent, Minnesota, USA). Elemental analyses were performed on a Leco CHNS-932 analyser (Leco, Michigan, USA). The TLC was performed to monitor reactions on silica gel $60 \mathrm{~F}_{254}$ (Merck) layer using petroleum ether: ethyl acetate $(3: 1 \mathrm{v} / \mathrm{v})$ for the first and third reaction steps and petroleum ether: ethyl acetate $(1: 1 \mathrm{v} / \mathrm{v})$ for the second and fourth reaction steps (Scheme 1).

2.2. General Procedure for 4-Substituted-1-nitrobenzene Derivatives (1a-1c). 4-Fluoro-1-nitrobenzene ( $4.24 \mathrm{~mL}, 0.04 \mathrm{~mol})$, $\mathrm{K}_{2} \mathrm{CO}_{3}(5.52 \mathrm{~g} 0.04 \mathrm{~mol})$, appropriate cyclic secondary amine $(0.04 \mathrm{~mol})$, and DMF $(10 \mathrm{~mL})$ were added into a vial $(30 \mathrm{~mL})$ of microwave synthesis reactor (Anton-Paar Monowave 300, Graz, Austria). The reaction mixture was heated under conditions of $200^{\circ} \mathrm{C}$ and 10 bars for $15 \mathrm{~min}$. After cooling, the mixture was poured into iced-water; precipitated product was washed with water, dried, and recrystallized from ethanol. 


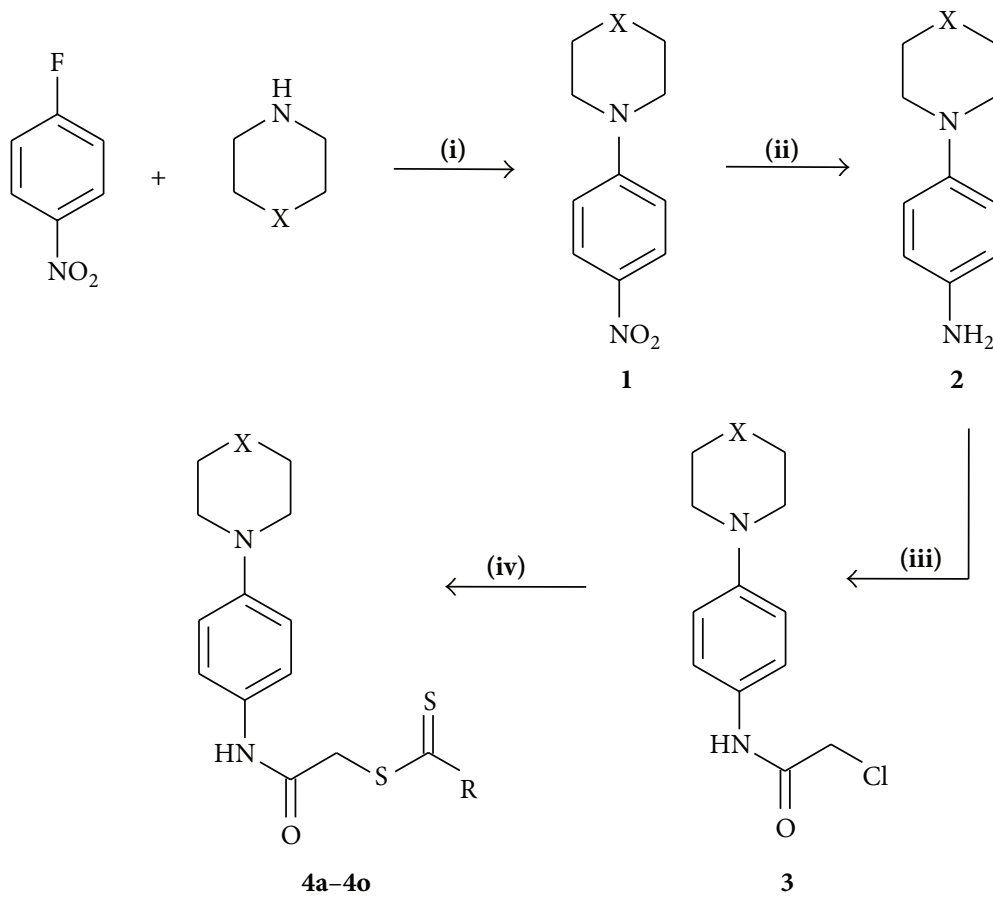

Scheme 1: The synthetic route for the preparation of dithiocarbamate derivatives. Reagents and conditions: (i) $\mathrm{K}_{2} \mathrm{CO}_{3}, \mathrm{DMF}_{\mathrm{N}}$ microwave irradiation, $15 \mathrm{~min}$; (ii) $\mathrm{Zn}$ powder, $25 \% \mathrm{HCl} / \mathrm{EtOH}$, room temperature $1 \mathrm{~h}$, and then reflux for $1 \mathrm{~h}$; (iii) $\mathrm{ClCH}_{2} \mathrm{COCl}$, TEA, THF ice bath and then room temperature $1 \mathrm{~h}$; (iv) corresponding dithiocarbamic acid sodium salt, acetone, reflux for $12 \mathrm{~h}$.

2.3. General Procedure for 4-Substituted Aniline Derivatives $(\mathbf{2} \boldsymbol{a}-\mathbf{2 c})$. Corresponding 4-substituted-1-nitrobenzene derivative (1a-1c) $(0.035 \mathrm{~mol})$ was dissolved in ethanol $(100 \mathrm{~mL})$ and $25 \% \mathrm{HCl}(100 \mathrm{~mL})$ mixture. Zinc powder $(22.75 \mathrm{~g}, 0.35 \mathrm{~mol})$ was divided into ten equal portions $(2.275 \mathrm{~g} \times 10)$ and each portion was added to the stirring solution in $15 \mathrm{~min}$ intervals. Once the addition of the zinc was completed reaction mixture was refluxed for $1 \mathrm{~h}$. Hot solution was allowed to cool down, poured into ice water, and then neutralized with $10 \% \mathrm{NaOH}$ solution. The precipitate was extracted with chloroform $(3 \times 100 \mathrm{~mL})$. The extracts were combined and filtered over anhydrous $\mathrm{Na}_{2} \mathrm{SO}_{4}$. The solvent was evaporated and the residue was recrystallized from ethanol to give the 4-substituted aniline derivatives (2a-2c).

\subsection{General Procedure for 2-Chloro-N-(4-substituted-phenyl)} acetamide $(\mathbf{3} \boldsymbol{a}-\mathbf{3} \boldsymbol{c})$. Appropriate 4 -substituted aniline (2a2c) $(0.022 \mathrm{~mol})$ and triethylamine $(3.2 \mathrm{~mL}, 0.22 \mathrm{~mol})$ were dissolved in THF $(100 \mathrm{~mL})$. This mixture was allowed to stir on an ice bath. Chloroacetyl chloride $(1.8 \mathrm{~mL}, 0.022 \mathrm{~mol})$ in THF $(10 \mathrm{~mL})$ was added drop by drop. After this stage, the content was stirred for $1 \mathrm{~h}$ at room temperature. THF was evaporated and the product was recrystallized from ethanol.

\subsection{N-[(4-Substituted-phenyl)-2-substituted thiocarbonylthio]} acetamide Derivatives $(\mathbf{4 a}-\mathbf{4 s})$. The compounds $\mathbf{3 a}-\mathbf{3 c}$ $(0.001 \mathrm{~mol})$ were stirred with appropriate sodium salt of dithiocarbamic acid $(0.0011 \mathrm{~mol})$ in acetone $(30 \mathrm{~mL})$ for $3 \mathrm{~h}$. The precipitated product was filtered, washed with water, and recrystallized from ethanol to gain the title products $4 \mathbf{a}-\mathbf{4 s}$.
2.5.1. N-[4-(Piperidin-1-yl)phenyl]-2-(dimethylaminothiocarbonylthio)acetamide (4a). IR (KBr) $\nu_{\max }\left(\mathrm{cm}^{-1}\right): 3288(\mathrm{~N}-$ $\mathrm{H}), 1651(\mathrm{C}=\mathrm{O}), 1217(\mathrm{C}=\mathrm{S}), 821$ (1,4-disubstituted benzene). ${ }^{1} \mathrm{H}-\mathrm{NMR}$ (500 MHz, DMSO-d6): 1.51-1.62 (m, 6H, piperidine, $\left.\mathrm{C}_{3,4,5}-\mathrm{H}\right), 3.05\left(\mathrm{~s}, 6 \mathrm{H},-\mathrm{N}\left(\mathrm{CH}_{3}\right)_{2}\right), 3.41-3.47(\mathrm{~m}, 4 \mathrm{H}$, piperidine, $\left.\mathrm{C}_{2,6}-\mathrm{H}\right), 4.17\left(\mathrm{~s}, 2 \mathrm{H},-\mathrm{COCH}_{2}\right), 6.87(\mathrm{~d}, 2 \mathrm{H}, J=$ $8.35 \mathrm{~Hz}$, phenyl, $\left.\mathrm{C}_{3,5}-\mathrm{H}\right), 7.40(\mathrm{~d}, 2 \mathrm{H}, J=8.54 \mathrm{~Hz}$, phenyl, $\left.\mathrm{C}_{2,6}-\mathrm{H}\right), 10.00$ (s, $\left.1 \mathrm{H},-\mathrm{NHCO}\right)$. MS (ESI) $(\mathrm{m} / \mathrm{z}):[\mathrm{M}+1]^{+}$ 338.16. Anal. Calcd. for $\mathrm{C}_{16} \mathrm{H}_{23} \mathrm{~N}_{3} \mathrm{OS}_{2}$ : C, 56.94; $\mathrm{H}, 6.87 ; \mathrm{N}$, 12.45; Found: C, 56.63; H, 6.85; N, 12.49 .

2.5.2. N-[4-(Piperidin-1-yl)phenyl]-2-(diethylaminothiocarbonylthio)acetamide $(\mathbf{4 b})$. IR $(\mathrm{KBr}) v_{\max }\left(\mathrm{cm}^{-1}\right): 3289(\mathrm{~N}-\mathrm{H})$, 1659 (C=O), 1236 (C=S), 824 (1,4-disubstituted benzene). ${ }^{1} \mathrm{H}$ NMR (500 MHz, DMSO-d6): $1.31(\mathrm{t}, 6 \mathrm{H}, J=7.14 \mathrm{~Hz},-$ $\left.\mathrm{N}\left(\mathrm{CH}_{2} \underline{\mathrm{CH}}_{3}\right)_{2}\right), 1.51-1.63$ (m, 6H, piperidine, $\left.\mathrm{C}_{3,4,5}-\mathrm{H}\right), 3.03$ $\left(\mathrm{q}, 4 \mathrm{H}, \mathrm{J}^{-}=7.21 \mathrm{~Hz},-\mathrm{N}\left(\mathrm{CH}_{2} \mathrm{CH}_{3}\right)_{2}\right), 3.39-3.49(\mathrm{~m}, 4 \mathrm{H}$, piperidine, $\left.\mathrm{C}_{2,6}-\mathrm{H}\right), 4.18\left(\mathrm{~s}, 2 \mathrm{H},-\mathrm{COCH}_{2}\right), 6.88(\mathrm{~d}, 2 \mathrm{H}, J=$ $8.53 \mathrm{~Hz}$, phenyl, $\left.\mathrm{C}_{3,5}-\mathrm{H}\right), 7.41(\mathrm{~d}, 2 \mathrm{H}, \mathrm{J}=8.62 \mathrm{~Hz}$, phenyl, $\left.\mathrm{C}_{2,6}-\mathrm{H}\right), 10.05$ (s, 1H, -NHCO). MS (ESI) $(\mathrm{m} / z):[\mathrm{M}+1]^{+}$ 366.18. Anal. Calcd. for $\mathrm{C}_{18} \mathrm{H}_{27} \mathrm{~N}_{3} \mathrm{OS}_{2}$ : C, 59.14; $\mathrm{H}, 7.44 ; \mathrm{N}$, 11.49; Found: C, 59.07; H, 7.42; N, 11.50 .

2.5.3. N-[4-(Piperidin-1-yl)phenyl]-2-(pyrrolidin-1-yl-thiocarbonylthio)acetamide $(4 c)$. IR $(\mathrm{KBr}) \nu_{\max }\left(\mathrm{cm}^{-1}\right): 3291(\mathrm{~N}-\mathrm{H})$, $1659(\mathrm{C}=\mathrm{O}), 1236(\mathrm{C}=\mathrm{S}), 822$ (1,4-disubstituted benzene). ${ }^{1} \mathrm{H}$ NMR (500 MHz, DMSO-d6): 1.51-1.62 (m, 6H, piperidine, $\left.\mathrm{C}_{3,4,5}-\mathrm{H}\right), 1.91-2.06\left(\mathrm{~m}, 4 \mathrm{H}\right.$, pyrrolidine, $\left.\mathrm{C}_{3,4}-\mathrm{H}\right), 3.04-3.09$ (m, $4 \mathrm{H}$, pyrrolidine, $\left.\mathrm{C}_{2,5}-\mathrm{H}\right), 3.41-3.47(\mathrm{~m}, 4 \mathrm{H}$, piperidine, 
$\left.\mathrm{C}_{2,6}-\mathrm{H}\right), 4.20\left(\mathrm{~s}, 2 \mathrm{H},-\mathrm{COCH}_{2}\right), 6.87(\mathrm{~d}, 2 \mathrm{H}, J=8.31 \mathrm{~Hz}$, phenyl, $\left.\mathrm{C}_{3,5}-\mathrm{H}\right), 7.40\left(\mathrm{~d}, 2 \mathrm{H}, J=8.39 \mathrm{~Hz}\right.$, phenyl, $\left.\mathrm{C}_{2,6}-\mathrm{H}\right)$, 9.99 (s, 1H, -NHCO). MS (ESI) $(\mathrm{m} / z)$ : $[\mathrm{M}+1]^{+}$364.11. Anal. Calcd. for $\mathrm{C}_{18} \mathrm{H}_{25} \mathrm{~N}_{3} \mathrm{OS}_{2}$ : C, 59.47; H, 6.93; N, 11.56; Found: C, 59.22; H, 6.91; N, 11.59.

2.5.4. N-[4-(Piperidin-1-yl)phenyl]-2-(piperidin-1-yl-thiocarbonylthio)acetamide $(\mathbf{4 d})$. IR $(\mathrm{KBr}) \nu_{\max }\left(\mathrm{cm}^{-1}\right): 3287(\mathrm{~N}-\mathrm{H})$, $1659(\mathrm{C}=\mathrm{O}), 1234$ ( $\mathrm{C}=\mathrm{S}), 822$ (1,4-disubstituted benzene). ${ }^{1} \mathrm{H}-\mathrm{NMR}$ (500 MHz, DMSO-d6): 1.51-1.66 (m, 12H, $2 \times$ piperidine, $\left.\mathrm{C}_{3,4,5}-\mathrm{H}\right), 3.04-3.08\left(\mathrm{~m}, 4 \mathrm{H}\right.$, piperidine, $\left.\mathrm{C}_{2,6}-\mathrm{H}\right)$, 3.41-3.47 (m, $4 \mathrm{H}$, piperidine, $\left.\mathrm{C}_{2,6}-\mathrm{H}\right), 4.20\left(\mathrm{~s}, 2 \mathrm{H},-\mathrm{COCH}_{2}\right)$, $6.87\left(\mathrm{~d}, 2 \mathrm{H}, J=8.36 \mathrm{~Hz}\right.$, phenyl, $\left.\mathrm{C}_{3,5}-\mathrm{H}\right), 7.40(\mathrm{~d}, 2 \mathrm{H}, J=$ 8.29 Hz, phenyl, $\left.\mathrm{C}_{2,6}-\mathrm{H}\right), 10.01$ (s, $\left.1 \mathrm{H},-\mathrm{NHCO}\right)$. MS (ESI) $(m / z):[\mathrm{M}+1]^{+}$378.19. Anal. Calcd. for $\mathrm{C}_{19} \mathrm{H}_{27} \mathrm{~N}_{3} \mathrm{OS}_{2}: \mathrm{C}$, 60.44; H, 7.21; N, 11.13; Found: C, 60.70; H, 7.19; N, 11.15.

2.5.5. N-[4-(Piperidin-1-yl)phenyl]-2-(4-methylpiperidin-1-ylthiocarbonylthio)acetamide (4e). IR (KBr) $\nu_{\max }\left(\mathrm{cm}^{-1}\right): 3291$ $(\mathrm{N}-\mathrm{H}), 1659(\mathrm{C}=\mathrm{O}), 1234(\mathrm{C}=\mathrm{S}), 822$ (1,4-disubstituted benzene). ${ }^{1} \mathrm{H}-\mathrm{NMR}(500 \mathrm{MHz}, \mathrm{DMSO}-\mathrm{d} 6): 0.93(\mathrm{~d}, 3 \mathrm{H}, J=$ $\left.7.11 \mathrm{~Hz},-\mathrm{CH}_{3}\right), 1.50-1.64\left(\mathrm{~m}, 11 \mathrm{H}, 2 \times\right.$ piperidine, $\mathrm{C}_{3,4,5}-$ $\mathrm{H}), 3.04-3.09\left(\mathrm{~m}, 4 \mathrm{H}\right.$, piperidine, $\left.\mathrm{C}_{2,6}-\mathrm{H}\right), 3.41-3.46(\mathrm{~m}, 4 \mathrm{H}$, piperidine, $\left.\mathrm{C}_{2,6}-\mathrm{H}\right), 4.19\left(\mathrm{~s}, 2 \mathrm{H},-\mathrm{COCH}_{2}\right), 6.87(\mathrm{~d}, 2 \mathrm{H}, J=$ $8.33 \mathrm{~Hz}$, phenyl, $\left.\mathrm{C}_{3,5}-\mathrm{H}\right), 7.40(\mathrm{~d}, 2 \mathrm{H}, J=8.43 \mathrm{~Hz}$, phenyl, $\left.\mathrm{C}_{2,6}-\mathrm{H}\right), 10.02$ (s, $\left.1 \mathrm{H},-\mathrm{NHCO}\right)$. MS (ESI) $(\mathrm{m} / z):[\mathrm{M}+1]^{+}$ 392.14. Anal. Calcd. for $\mathrm{C}_{20} \mathrm{H}_{29} \mathrm{~N}_{3} \mathrm{OS}_{2}$ : C, 61.34; H, 7.46; N, 10.73; Found: C, 61.42; H, 7.45; N, 10.70.

2.5.6. N-[4-(Piperidin-1-yl)phenyl]-2-(4-benzylpiperidin-1-ylthiocarbonylthio)acetamide (4f). IR $(\mathrm{KBr}) \nu_{\max }\left(\mathrm{cm}^{-1}\right): 3289$ $(\mathrm{N}-\mathrm{H}), 1659(\mathrm{C}=\mathrm{O}), 1234(\mathrm{C}=\mathrm{S}), 822$ (1,4-disubstituted benzene). ${ }^{1} \mathrm{H}-\mathrm{NMR}$ (500 MHz, DMSO-d6): 1.44-1.63 (m, 11H, $2 \times$ piperidine, $\left.\mathrm{C}_{3,4,5}-\mathrm{H}\right), 2.54(\mathrm{~d}, 2 \mathrm{H}, J=7.14 \mathrm{~Hz}$, $-\mathrm{CH}_{2} \mathrm{C}_{6} \mathrm{H}_{5}$ ), 3.04-3.10 (m, $4 \mathrm{H}$, piperidine, $\mathrm{C}_{2,6}-\mathrm{H}$ ), 3.42$3.48\left(\mathrm{~m}, 4 \mathrm{H}\right.$, piperidine, $\left.\mathrm{C}_{2,6}-\mathrm{H}\right), 4.19\left(\mathrm{~s}, 2 \mathrm{H},-\mathrm{COCH}_{2}\right)$, $6.87\left(\mathrm{~d}, 2 \mathrm{H}, J=8.22 \mathrm{~Hz}\right.$, phenyl, $\left.\mathrm{C}_{3,5}-\mathrm{H}\right), 7.19-7.31(\mathrm{~m}, 5 \mathrm{H}$, $\left.-\mathrm{CH}_{2} \underline{\mathrm{C}}_{6} \underline{\mathrm{H}}_{5}\right), 7.41\left(\mathrm{~d}, 2 \mathrm{H}, J=8.30 \mathrm{~Hz}\right.$, phenyl, $\left.\mathrm{C}_{2,6}-\mathrm{H}\right), 10.02$ (s, $1 \mathrm{H},-\overline{\mathrm{NH}} \mathrm{CO})$. MS (ESI) $(\mathrm{m} / z):[\mathrm{M}+1]^{+}$468.17. Anal. Calcd. for $\mathrm{C}_{26} \mathrm{H}_{33} \mathrm{~N}_{3} \mathrm{OS}_{2}$ : C, 66.77; H, 7.11; N, 8.98; Found: C, 66.59; $\mathrm{H}, 7.09$; N, 9.00.

2.5.7. N-[4-(Morpholin-4-yl)phenyl]-2-(dimethylaminothiocarbonylthio)acetamide (4g). IR (KBr) $v_{\max }\left(\mathrm{cm}^{-1}\right): 3287(\mathrm{~N}-$ $\mathrm{H}), 1659(\mathrm{C}=\mathrm{O}), 1234(\mathrm{C}=\mathrm{S}), 822$ (1,4-disubstituted benzene). ${ }^{1} \mathrm{H}-\mathrm{NMR}$ (500 MHz, DMSO-d6): 3.04 (s, 6H, -N $\left(\mathrm{CH}_{3}\right)_{2}$ ), 3.41-3.47 (m, 4H, morpholine, $\left.\mathrm{C}_{3,5}-\mathrm{H}\right), 3.72-3.74(\mathrm{~m}, 4 \mathrm{H}$, morpholine, $\left.\mathrm{C}_{2,6}-\mathrm{H}\right), 4.18\left(\mathrm{~s}, 2 \mathrm{H},-\mathrm{COCH}_{2}\right), 6.89(\mathrm{~d}, 2 \mathrm{H}$, $J=8.32 \mathrm{~Hz}$, phenyl, $\left.\mathrm{C}_{3,5}-\mathrm{H}\right), 7.44(\mathrm{~d}, 2 \mathrm{H}, J=8.44 \mathrm{~Hz}$, phenyl, $\left.\mathrm{C}_{2,6}-\mathrm{H}\right), 10.01(\mathrm{~s}, 1 \mathrm{H},-\mathrm{NHCO})$. MS (ESI) $(\mathrm{m} / \mathrm{z}):[\mathrm{M}+$ $1]^{+}$340.15. Anal. Calcd. for $\mathrm{C}_{15} \mathrm{H}_{21} \mathrm{~N}_{3} \mathrm{OS}_{2}$ : C, 53.07; $\mathrm{H}, 6.24$; $\mathrm{N}, 12.38$; Found: C, 53.33; H, 6.25; N, 12.36.

2.5.8. N-[4-(Morpholin-4-yl)phenyl]-2-(diethylaminothiocarbonylthio)acetamide (4h). IR (KBr) $\nu_{\max }\left(\mathrm{cm}^{-1}\right): 3289(\mathrm{~N}-$ $\mathrm{H}), 1659(\mathrm{C}=\mathrm{O}), 1235$ (C=S), 822 (1,4-disubstituted benzene).
${ }^{1} \mathrm{H}-\mathrm{NMR}$ (500 MHz, DMSO-d6): 1.23 (t, 6H, $J=7.18 \mathrm{~Hz},-$ $\left.\mathrm{N}\left(\mathrm{CH}_{2} \underline{\mathrm{CH}}_{3}\right)_{2}\right), 3.04\left(\mathrm{q}, 4 \mathrm{H}, J=7.16 \mathrm{~Hz},-\mathrm{N}\left(\underline{\mathrm{CH}}_{2} \mathrm{CH}_{3}\right)_{2}\right)$, 3.39-3.49 (m, 4H, morpholine, $\left.\mathrm{C}_{3,5}-\mathrm{H}\right), 3.72-3.76(\mathrm{~m}, 4 \mathrm{H}$, morpholine, $\left.\mathrm{C}_{2,6}-\mathrm{H}\right), 4.19\left(\mathrm{~s}, 2 \mathrm{H},-\mathrm{COCH}_{2}\right), 6.89(\mathrm{~d}, 2 \mathrm{H}$, $J=8.33 \mathrm{~Hz}$, phenyl, $\left.\mathrm{C}_{3,5}-\mathrm{H}\right), 7.45(\mathrm{~d}, 2 \mathrm{H}, J=8.29 \mathrm{~Hz}$, phenyl, $\left.\mathrm{C}_{2,6}-\mathrm{H}\right), 10.06$ (s, 1H, -NHCO). MS (ESI) $(\mathrm{m} / \mathrm{z}):[\mathrm{M}+1]^{+}$ 368.12. Anal. Calcd. for $\mathrm{C}_{17} \mathrm{H}_{25} \mathrm{~N}_{3} \mathrm{O}_{2} \mathrm{~S}_{2}$ : C, 55.56; H, 6.86; N, 11.43; Found: C, 56.62; H, 6.85; N, 11.41 .

2.5.9. N-[4-(Morpholin-4-yl)phenyl]-2-(pyrrolidin-1-yl-thiocarbonylthio)acetamide (4i). IR (KBr) $\nu_{\max }\left(\mathrm{cm}^{-1}\right): 3287(\mathrm{~N}-\mathrm{H})$, $1659(\mathrm{C}=\mathrm{O}), 1234(\mathrm{C}=\mathrm{S}), 822$ (1,4-disubstituted benzene). ${ }^{1} \mathrm{H}$ NMR (500 MHz, DMSO-d6): 1.93-2.07 (m, 4H, pyrrolidine, $\left.\mathrm{C}_{3,4}-\mathrm{H}\right), 3.03-3.06\left(\mathrm{~m}, 4 \mathrm{H}\right.$, pyrrolidine, $\left.\mathrm{C}_{2,5}-\mathrm{H}\right)$, 3.41-3.48 ( $\mathrm{m}, 4 \mathrm{H}$, morpholine, $\left.\mathrm{C}_{3,5}-\mathrm{H}\right), 3.73-3.82(\mathrm{~m}, 4 \mathrm{H}$, morpholine, $\left.\mathrm{C}_{2,6}-\mathrm{H}\right), 4.21\left(\mathrm{~s}, 2 \mathrm{H},-\mathrm{COCH}_{2}\right), 6.89(\mathrm{~d}, 2 \mathrm{H}, J=8.36 \mathrm{~Hz}$, phenyl, $\left.\mathrm{C}_{3,5}-\mathrm{H}\right), 7.44\left(\mathrm{~d}, 2 \mathrm{H}, \mathrm{J}=8.31 \mathrm{~Hz}\right.$, phenyl, $\left.\mathrm{C}_{2,6}-\mathrm{H}\right)$, 10.05 (s, $1 \mathrm{H},-\mathrm{NHCO})$. MS (ESI) $(\mathrm{m} / \mathrm{z})$ : $[\mathrm{M}+1]^{+}$336.17. Anal. Calcd. for $\mathrm{C}_{17} \mathrm{H}_{23} \mathrm{~N}_{3} \mathrm{O}_{2} \mathrm{~S}_{2}$ : C, 55.86; H, 6.34; N, 11.50; Found: C, 55.94; H, 6.37; N, 11.51.

2.5.10. N-[4-(Morpholin-4-yl)phenyl]-2-(piperidin-1-yl-thiocarbonylthio)acetamide (4j). IR $(\mathrm{KBr}) \nu_{\max }\left(\mathrm{cm}^{-1}\right): 3289(\mathrm{~N}-\mathrm{H})$, $1651(\mathrm{C}=\mathrm{O}), 1217(\mathrm{C}=\mathrm{S}), 821$ (1,4-disubstituted benzene). ${ }^{1} \mathrm{H}$ NMR (500 MHz, DMSO-d6): 1.56-1.64 (m, 6H, piperidine, $\left.\mathrm{C}_{3,4,5}-\mathrm{H}\right), 3.03-3.06\left(\mathrm{~m}, 4 \mathrm{H}\right.$, piperidine, $\left.\mathrm{C}_{2,6}-\mathrm{H}\right), 3.41-3.48$ (m, $4 \mathrm{H}$, morpholine, $\left.\mathrm{C}_{3,5}-\mathrm{H}\right), 3.73-3.86(\mathrm{~m}, 4 \mathrm{H}$, morpholine, $\left.\mathrm{C}_{2,6}-\mathrm{H}\right), 4.20\left(\mathrm{~s}, 2 \mathrm{H},-\mathrm{COCH}_{2}\right), 6.89(\mathrm{~d}, 2 \mathrm{H}, J=8.42 \mathrm{~Hz}$, phenyl, $\left.\mathrm{C}_{3,5}-\mathrm{H}\right), 7.44\left(\mathrm{~d}, 2 \mathrm{H}, J=8.38 \mathrm{~Hz}\right.$, phenyl, $\left.\mathrm{C}_{2,6}-\mathrm{H}\right)$, 10.05 (s, $1 \mathrm{H},-\mathrm{NHCO})$. MS (ESI) $(\mathrm{m} / z)$ : $[\mathrm{M}+1]^{+}$380.15. Anal. Calcd. for $\mathrm{C}_{18} \mathrm{H}_{25} \mathrm{~N}_{3} \mathrm{O}_{2} \mathrm{~S}_{2}$ : C, 56.96; H, 6.64; N, 11.07; Found: C, 57.10; H, 6.67; N, 11.08.

2.5.11. N-[4-(Morpholin-4-yl)phenyl]-2-(4-methylpiperidin-1-ylthiocarbonylthio)acetamide (4k). IR $(\mathrm{KBr}) \nu_{\max }\left(\mathrm{cm}^{-1}\right): 3288$ $(\mathrm{N}-\mathrm{H}), 1659(\mathrm{C}=\mathrm{O}), 1234(\mathrm{C}=\mathrm{S}), 822$ (1,4-disubstituted benzene). ${ }^{1} \mathrm{H}-\mathrm{NMR}$ (500 MHz, DMSO-d6): 0.94 (d, 3H, $J=$ $\left.7.14 \mathrm{~Hz},-\mathrm{CH}_{3}\right), 1.50-1.65\left(\mathrm{~m}, 5 \mathrm{H}\right.$, piperidine, $\left.\mathrm{C}_{3,4,5}-\mathrm{H}\right)$, 3.03-3.09 (m, 4H, piperidine, $\left.\mathrm{C}_{2,6}-\mathrm{H}\right), 3.40-3.46(\mathrm{~m}, 4 \mathrm{H}$, morpholine, $\left.\mathrm{C}_{3,5}-\mathrm{H}\right), 3.71-3.77\left(\mathrm{~m}, 4 \mathrm{H}\right.$, morpholine, $\mathrm{C}_{2,6}$ $\mathrm{H}), 4.19\left(\mathrm{~s}, 2 \mathrm{H},-\mathrm{COCH}_{2}\right), 6.88(\mathrm{~d}, 2 \mathrm{H}, J=8.31 \mathrm{~Hz}$, phenyl, $\left.\mathrm{C}_{3,5}-\mathrm{H}\right), 7.42\left(\mathrm{~d}, 2 \mathrm{H}, J=8.39 \mathrm{~Hz}\right.$, phenyl, $\left.\mathrm{C}_{2,6}-\mathrm{H}\right), 10.02(\mathrm{~s}$, $1 \mathrm{H},-\mathrm{NHCO})$. MS (ESI) $(\mathrm{m} / z):[\mathrm{M}+1]^{+}$394.18. Anal. Calcd. for $\mathrm{C}_{19} \mathrm{H}_{27} \mathrm{~N}_{3} \mathrm{O}_{2} \mathrm{~S}_{2}$ : C, 57.98; H, 6.91; N, 10.68; Found: C, 58.08; $\mathrm{H}, 6.92 ; \mathrm{N}, 10.69$.

2.5.12. N-[4-(Morpholin-4-yl)phenyl]-2-(4-benzylpiperidin-1$y$ l-thiocarbonylthio)acetamide (4l). IR (KBr) $\nu_{\max }\left(\mathrm{cm}^{-1}\right)$ : $3289(\mathrm{~N}-\mathrm{H}), 1659(\mathrm{C}=\mathrm{O}), 1233(\mathrm{C}=\mathrm{S}), 822$ (1,4-disubstituted benzene). ${ }^{1} \mathrm{H}-\mathrm{NMR}(500 \mathrm{MHz}$, DMSO-d6): 1.51-1.62 (m, 5H, piperidine, $\left.\mathrm{C}_{3,4,5}-\mathrm{H}\right), 2.52\left(\mathrm{~d}, 2 \mathrm{H}, J=7.22 \mathrm{~Hz},-\mathrm{CH}_{2} \mathrm{C}_{6} \mathrm{H}_{5}\right)$, 3.05-3.08 (m, $4 \mathrm{H}$, piperidine, $\left.\mathrm{C}_{2,6}-\mathrm{H}\right), 3.41-3.47(\mathrm{~m}, 4 \mathrm{H}$, morpholine, $\left.\mathrm{C}_{3,5}-\mathrm{H}\right), 3.72-3.78\left(\mathrm{~m}, 4 \mathrm{H}\right.$, morpholine, $\mathrm{C}_{2,6}{ }^{-}$ $\mathrm{H}), 4.18\left(\mathrm{~s}, 2 \mathrm{H},-\mathrm{COCH}_{2}\right), 6.89(\mathrm{~d}, 2 \mathrm{H}, \mathrm{J}=8.38 \mathrm{~Hz}$, phenyl, $\left.\mathrm{C}_{3,5}-\mathrm{H}\right), 7.19-7.31\left(\mathrm{~m}, 5 \mathrm{H},-\mathrm{CH}_{2} \underline{\mathrm{C}}_{6} \underline{\mathrm{H}}_{5}\right), 7.41(\mathrm{~d}, 2 \mathrm{H}, J=$ $8.43 \mathrm{~Hz}$, phenyl, $\left.\mathrm{C}_{2,6}-\mathrm{H}\right), 10.04$ (s, $\left.\overline{1} \mathrm{H}^{-},-\mathrm{NHCO}\right)$. MS (ESI) 
TABLE 1: Some physicochemical properties of the synthesized compounds.

\begin{tabular}{|c|c|c|c|c|c|c|c|c|}
\hline Comp. & 2. $\mathrm{X}$ & $\mathrm{R}$ & Yield (\%) & M.p. $\left({ }^{\circ} \mathrm{C}\right)$ & M.p. $\left({ }^{\circ} \mathrm{C}\right)$ [Lit.] & Molecular formula & $\begin{array}{c}\text { Molecular weight } \\
(\mathrm{g} / \mathrm{mol})\end{array}$ & Appearance \\
\hline 1a & $\mathrm{CH}_{2}$ & - & 73 & 97 & 95 [31] & $\mathrm{C}_{11} \mathrm{H}_{14} \mathrm{~N}_{2} \mathrm{O}_{2}$ & 206 & Yellow \\
\hline $1 b$ & $\mathrm{O}$ & - & 69 & 161 & $158-159[32]$ & $\mathrm{C}_{10} \mathrm{H}_{12} \mathrm{~N}_{2} \mathrm{O}_{3}$ & 208 & Yellow \\
\hline $1 c$ & $\mathrm{~N}-\mathrm{CH}_{3}$ & - & 79 & 106 & $105-106[33]$ & $\mathrm{C}_{11} \mathrm{H}_{15} \mathrm{~N}_{3} \mathrm{O}_{2}$ & 221 & Yellow \\
\hline $2 a$ & $\mathrm{CH}_{2}$ & - & 42 & 41 & $40[34]$ & $\mathrm{C}_{11} \mathrm{H}_{16} \mathrm{~N}_{2}$ & 176 & White \\
\hline $2 b$ & $\mathrm{O}$ & - & 51 & 131 & $129.5-130.5[35]$ & $\mathrm{C}_{10} \mathrm{H}_{14} \mathrm{~N}_{2} \mathrm{O}$ & 178 & Brown \\
\hline $2 c$ & $\mathrm{~N}-\mathrm{CH}_{3}$ & - & 49 & 92 & $93[36]$ & $\mathrm{C}_{11} \mathrm{H}_{17} \mathrm{~N}_{3}$ & 191 & White \\
\hline $3 a$ & $\mathrm{CH}_{2}$ & - & 79 & 132 & - & $\mathrm{C}_{13} \mathrm{H}_{17} \mathrm{ClN}_{2} \mathrm{O}$ & 252.5 & Brown \\
\hline $3 b$ & $\mathrm{O}$ & - & 81 & 171 & $170-172$ [37] & $\mathrm{C}_{12} \mathrm{H}_{15} \mathrm{ClN}_{2} \mathrm{O}_{2}$ & 254.5 & Brown \\
\hline $3 c$ & $\mathrm{~N}-\mathrm{CH}_{3}$ & - & 76 & 186 & - & $\mathrm{C}_{13} \mathrm{H}_{18} \mathrm{ClN}_{3} \mathrm{O}$ & 267.5 & Brown \\
\hline $4 a$ & $\mathrm{CH}_{2}$ & $-\mathrm{N}\left(\mathrm{CH}_{3}\right)_{2}$ & 75 & 142 & - & $\mathrm{C}_{16} \mathrm{H}_{23} \mathrm{~N}_{3} \mathrm{OS}_{2}$ & 337 & Cream-colored \\
\hline $4 b$ & $\mathrm{CH}_{2}$ & $-\mathrm{N}\left(\mathrm{C}_{2} \mathrm{H}_{5}\right)_{2}$ & 83 & 127 & - & $\mathrm{C}_{18} \mathrm{H}_{27} \mathrm{~N}_{3} \mathrm{OS}_{2}$ & 365 & Brown \\
\hline $4 c$ & $\mathrm{CH}_{2}$ & Pyrrolidin-1-yl & 85 & 163 & - & $\mathrm{C}_{18} \mathrm{H}_{25} \mathrm{~N}_{3} \mathrm{OS}_{2}$ & 363 & Cream-colored \\
\hline $4 d$ & $\mathrm{CH}_{2}$ & Piperidin-1-yl & 82 & 235 & - & $\mathrm{C}_{19} \mathrm{H}_{27} \mathrm{~N}_{3} \mathrm{OS}_{2}$ & 391 & Cream-colored \\
\hline $4 e$ & $\mathrm{CH}_{2}$ & 4-Methylpiperidin -1-yl & 79 & 212 & - & $\mathrm{C}_{20} \mathrm{H}_{29} \mathrm{~N}_{3} \mathrm{OS}_{2}$ & 405 & Brown \\
\hline $4 f$ & $\mathrm{CH}_{2}$ & 4-Benzylpiperidin-1-yl & 84 & 220 & - & $\mathrm{C}_{26} \mathrm{H}_{33} \mathrm{~N}_{3} \mathrm{OS}_{2}$ & 481 & Brown \\
\hline $4 g$ & $\mathrm{O}$ & $-\mathrm{N}\left(\mathrm{CH}_{3}\right)_{2}$ & 87 & 148 & - & $\mathrm{C}_{15} \mathrm{H}_{21} \mathrm{~N}_{3} \mathrm{OS}_{2}$ & 339 & Brown \\
\hline $4 h$ & $\mathrm{O}$ & $-\mathrm{N}\left(\mathrm{C}_{2} \mathrm{H}_{5}\right)_{2}$ & 78 & 97 & - & $\mathrm{C}_{17} \mathrm{H}_{25} \mathrm{~N}_{3} \mathrm{O}_{2} \mathrm{~S}_{2}$ & 367 & White \\
\hline $4 \mathbf{i}$ & $\mathrm{O}$ & Pyrrolidin-1-yl & 73 & 175 & - & $\mathrm{C}_{17} \mathrm{H}_{23} \mathrm{~N}_{3} \mathrm{O}_{2} \mathrm{~S}_{2}$ & 365 & Cream-colored \\
\hline $4 j$ & $\mathrm{O}$ & Piperidin-1-yl & 77 & 171 & - & $\mathrm{C}_{18} \mathrm{H}_{25} \mathrm{~N}_{3} \mathrm{O}_{2} \mathrm{~S}_{2}$ & 393 & Brown \\
\hline $4 k$ & $\mathrm{O}$ & 4-Methylpiperidin -1-yl & 69 & 165 & - & $\mathrm{C}_{19} \mathrm{H}_{27} \mathrm{~N}_{3} \mathrm{O}_{2} \mathrm{~S}_{2}$ & 407 & Cream-colored \\
\hline 41 & $\mathrm{O}$ & 4-Benzylpiperidin-1-yl & 72 & 150 & - & $\mathrm{C}_{25} \mathrm{H}_{31} \mathrm{~N}_{3} \mathrm{O}_{2} \mathrm{~S}_{2}$ & 483 & Cream-colored \\
\hline $4 \mathrm{~m}$ & $\mathrm{~N}-\mathrm{CH}_{3}$ & $-\mathrm{N}\left(\mathrm{CH}_{3}\right)_{2}$ & 70 & 185 & - & $\mathrm{C}_{16} \mathrm{H}_{24} \mathrm{~N}_{4} \mathrm{OS}_{2}$ & 352 & Brown \\
\hline $4 n$ & $\mathrm{~N}-\mathrm{CH}_{3}$ & $-\mathrm{N}\left(\mathrm{C}_{2} \mathrm{H}_{5}\right)_{2}$ & 78 & 152 & - & $\mathrm{C}_{18} \mathrm{H}_{26} \mathrm{~N}_{4} \mathrm{OS}_{2}$ & 380 & White \\
\hline 40 & $\mathrm{~N}-\mathrm{CH}_{3}$ & Pyrrolidin-1-yl & 73 & 175 & - & $\mathrm{C}_{19} \mathrm{H}_{28} \mathrm{~N}_{4} \mathrm{OS}_{2}$ & 378 & Cream-colored \\
\hline $4 p$ & $\mathrm{~N}-\mathrm{CH}_{3}$ & Piperidin-1-yl & 75 & 147 & - & $\mathrm{C}_{20} \mathrm{H}_{30} \mathrm{~N}_{4} \mathrm{OS}_{2}$ & 406 & Brown \\
\hline $4 r$ & $\mathrm{~N}-\mathrm{CH}_{3}$ & 4-Methylpiperidin-1yl & 71 & 179 & - & $\mathrm{C}_{26} \mathrm{H}_{34} \mathrm{~N}_{4} \mathrm{OS}_{2}$ & 420 & Brown \\
\hline $4 \mathrm{~s}$ & $\mathrm{~N}-\mathrm{CH}_{3}$ & 4-Benzylpiperidin-1-yl & 82 & 155 & - & $\mathrm{C}_{16} \mathrm{H}_{24} \mathrm{~N}_{4} \mathrm{OS}_{2}$ & 496 & Cream-colored \\
\hline
\end{tabular}

$(m / z):[\mathrm{M}+1]^{+}$470.21. Anal. Calcd. for $\mathrm{C}_{25} \mathrm{H}_{31} \mathrm{~N}_{3} \mathrm{O}_{2} \mathrm{~S}_{2}$ : C, 63.93; H, 6.65; N, 8.95; Found: C, 63.75; H, 6.63; N, 8.98.

2.5.13. N-[4-(4-Methylpiperazin-1-yl)phenyl]-2-(dimethylaminothiocarbonylthio)acetamide (4m). IR $(\mathrm{KBr}) v_{\max }\left(\mathrm{cm}^{-1}\right)$ : $3273(\mathrm{~N}-\mathrm{H}), 1654(\mathrm{C}=\mathrm{O}), 1221(\mathrm{C}=\mathrm{S}), 822$ (1,4-disubstituted benzene). ${ }^{1} \mathrm{H}-\mathrm{NMR}(500 \mathrm{MHz}, \mathrm{DMSO}-\mathrm{d} 6): 2.22$ (s, 3H, $\left.\mathrm{NCH}_{3}\right), 3.06\left(\mathrm{~s}, 6 \mathrm{H},-\mathrm{N}\left(\mathrm{CH}_{3}\right)_{2}\right), 3.39-3.57(\mathrm{~m}, 8 \mathrm{H}$, piperazine, $\left.\mathrm{C}_{2,3,5,6}-\mathrm{H}\right), 4.18\left(\mathrm{~s}, 2 \mathrm{H},-\mathrm{COCH}_{2}\right), 6.88(\mathrm{~d}, 2 \mathrm{H}, J=$ $8.25 \mathrm{~Hz}$, phenyl, $\left.\mathrm{C}_{3,5}-\mathrm{H}\right), 7.42(\mathrm{~d}, 2 \mathrm{H}, J=8.28 \mathrm{~Hz}$, phenyl, $\left.\mathrm{C}_{2,6}-\mathrm{H}\right), 10.02(\mathrm{~s}, 1 \mathrm{H},-\mathrm{NHCO})$. MS (ESI) $(\mathrm{m} / z):[\mathrm{M}+1]^{+}$ 353.11. Anal. Calcd. for $\mathrm{C}_{16} \mathrm{H}_{24} \mathrm{~N}_{4} \mathrm{OS}_{2}: \mathrm{C}, 54.51 ; \mathrm{H}, 6.86 ; \mathrm{N}$, 15.89; Found: C, 54.38; H, 6.84; N, 15.84 .

2.5.14. N-[4-(4-Methylpiperazin-1-yl)phenyl]-2-(diethylaminothiocarbonylthio)acetamide (4n). IR $(\mathrm{KBr}) \nu_{\max }\left(\mathrm{cm}^{-1}\right): 3292$ $(\mathrm{N}-\mathrm{H}), 1654(\mathrm{C}=\mathrm{O}), 1234(\mathrm{C}=\mathrm{S}), 820$ (1,4-disubstituted benzene). ${ }^{1} \mathrm{H}-\mathrm{NMR}(500 \mathrm{MHz}, \mathrm{DMSO}-\mathrm{d} 6): 1.23(\mathrm{t}, 6 \mathrm{H}, J=$ $\left.7.11 \mathrm{~Hz},-\mathrm{N}\left(\mathrm{CH}_{2} \mathrm{CH}_{3}\right)_{2}\right), 2.24\left(\mathrm{~s}, 3 \mathrm{H},-\mathrm{NCH}_{3}\right), 3.06(\mathrm{q}, 4 \mathrm{H}$, $\left.J=7.16 \mathrm{~Hz},-\mathrm{N}\left(\mathrm{CH}_{2} \mathrm{CH}_{3}\right)_{2}\right), 3.39-3.62(\mathrm{~m}, 8 \mathrm{H}$, piperazine, $\left.\mathrm{C}_{2,3,5,6}-\mathrm{H}\right), 4.18\left(\mathrm{~s}, 2 \mathrm{H},-\mathrm{COCH}_{2}\right), 6.88(\mathrm{~d}, 2 \mathrm{H}, J=8.19 \mathrm{~Hz}$, phenyl, $\left.\mathrm{C}_{3,5}-\mathrm{H}\right), 7.42\left(\mathrm{~d}, 2 \mathrm{H}, J=8.32 \mathrm{~Hz}\right.$, phenyl, $\left.\mathrm{C}_{2,6}-\mathrm{H}\right)$, 10.03 (s, 1H, -NHCO). MS (ESI) $(\mathrm{m} / z)$ : $[\mathrm{M}+1]^{+}$381.16. Anal. Calcd. for $\mathrm{C}_{18} \mathrm{H}_{28} \mathrm{~N}_{4} \mathrm{OS}_{2}$ : C, 56.81; H, 7.42; N, 14.72; Found: C, $56.58 ; \mathrm{H}, 7.44 ; \mathrm{N}, 14.75$.

2.5.15. N-[4-(4-Methylpiperazin-1-yl)phenyl]-2-(pyrrolidin-1yl-thiocarbonylthio)acetamide (4o). IR $(\mathrm{KBr}) \nu_{\max }\left(\mathrm{cm}^{-1}\right)$ : $3287(\mathrm{~N}-\mathrm{H}), 1654(\mathrm{C}=\mathrm{O}), 1234(\mathrm{C}=\mathrm{S}), 820$ (1,4-disubstituted benzene). ${ }^{1} \mathrm{H}-\mathrm{NMR}$ (500 MHz, DMSO-d6): 2.06-2.10 (m, $4 \mathrm{H}$, pyrrolidine, $\left.\mathrm{C}_{3,4}-\mathrm{H}\right), 2.22\left(\mathrm{~s}, 3 \mathrm{H},-\mathrm{NCH}_{3}\right), 3.04-3.08$ $\left(\mathrm{m}, 4 \mathrm{H}\right.$, pyrrolidine, $\left.\mathrm{C}_{2,5}-\mathrm{H}\right), 3.42-3.65(\mathrm{~m}, 8 \mathrm{H}$, piperazine, $\left.\mathrm{C}_{2,3,5,6}-\mathrm{H}\right), 4.20\left(\mathrm{~s}, 2 \mathrm{H},-\mathrm{COCH}_{2}\right), 6.88(\mathrm{~d}, 2 \mathrm{H}, J=8.12 \mathrm{~Hz}$, phenyl, $\left.\mathrm{C}_{3,5}-\mathrm{H}\right), 7.41\left(\mathrm{~d}, 2 \mathrm{H}, J=8.23 \mathrm{~Hz}\right.$, phenyl, $\left.\mathrm{C}_{2,6}-\mathrm{H}\right)$, $10.00(\mathrm{~s}, 1 \mathrm{H},-\mathrm{NHCO})$. MS (ESI) $(\mathrm{m} / \mathrm{z}):[\mathrm{M}+1]^{+}$379.17. Anal. Calcd. for $\mathrm{C}_{18} \mathrm{H}_{26} \mathrm{~N}_{4} \mathrm{OS}_{2}$ : C, 57.11; H, 6.92; N, 14.80; Found: C, 57.42; H, 6.94; N, 14.75 .

2.5.16. N-[4-(4-Methylpiperazin-1-yl)phenyl]-2-(piperidin-1-ylthiocarbonylthio)acetamide (4p). IR $(\mathrm{KBr}) \nu_{\max }\left(\mathrm{cm}^{-1}\right): 3291$ $(\mathrm{N}-\mathrm{H}), 1661(\mathrm{C}=\mathrm{O}), 1234(\mathrm{C}=\mathrm{S}), 820$ (1,4-disubstituted benzene). ${ }^{1} \mathrm{H}-\mathrm{NMR}$ (500 MHz, DMSO-d6): 1.56-1.68 (m, 6H, 
piperidine, $\left.\mathrm{C}_{3,4,5}-\mathrm{H}\right), 2.24\left(\mathrm{~s}, 3 \mathrm{H},-\mathrm{NCH}_{3}\right), 3.03-3.08(\mathrm{~m}, 4 \mathrm{H}$, piperidine, $\left.\mathrm{C}_{2,6}-\mathrm{H}\right), 3.41-3.68\left(\mathrm{~m}, 8 \mathrm{H}\right.$, piperazine, $\left.\mathrm{C}_{2,3,5,6}-\mathrm{H}\right)$, 4.19 (s, 2H, $\left.-\mathrm{COCH}_{2}\right), 6.88\left(\mathrm{~d}, 2 \mathrm{H}, \mathrm{J}=8.24 \mathrm{~Hz}\right.$, phenyl, $\mathrm{C}_{3,5}{ }^{-}$ $\mathrm{H}), 7.42\left(\mathrm{~d}, 2 \mathrm{H}, J=8.31 \mathrm{~Hz}\right.$, phenyl, $\left.\mathrm{C}_{2,6}-\mathrm{H}\right), 10.03(\mathrm{~s}, 1 \mathrm{H}$, -NHCO). MS (ESI) $(m / z):[\mathrm{M}+1]^{+}$393.13. Anal. Calcd. for $\mathrm{C}_{19} \mathrm{H}_{28} \mathrm{~N}_{4} \mathrm{OS}_{2}$ : C, 58.13; H, 7.19; N, 14.27; Found: C, 58.42; H, 7.21; N, 14.25.

2.5.17. N-[4-(4-Methylpiperazin-1-yl)phenyl]-2-(4-methylpiperidin-1-yl-thiocarbonylthio)acetamide (4r). IR (KBr) $v_{\max }$ $\left(\mathrm{cm}^{-1}\right): 3293(\mathrm{~N}-\mathrm{H}), 1661(\mathrm{C}=\mathrm{O}), 1234(\mathrm{C}=\mathrm{S}), 820(1,4-$ disubstituted benzene). ${ }^{1} \mathrm{H}-\mathrm{NMR}(500 \mathrm{MHz}, \mathrm{DMSO}-\mathrm{d} 6)$ : $0.96\left(\mathrm{~d}, 3 \mathrm{H}, J=7.08 \mathrm{~Hz},-\mathrm{CH}_{3}\right), 1.52-1.65(\mathrm{~m}, 5 \mathrm{H}$, piperidine, $\mathrm{C}_{3,4,5}-\mathrm{H}$ ), 3.04-3.08 (m, 4H, piperidine, $\left.\mathrm{C}_{2,6}-\mathrm{H}\right), 3.41-3.75$ $\left(\mathrm{m}, 8 \mathrm{H}\right.$, piperazine, $\left.\mathrm{C}_{2,3,5,6}-\mathrm{H}\right), 4.19\left(\mathrm{~s}, 2 \mathrm{H},-\mathrm{COCH}_{2}\right), 6.88$ $\left(\mathrm{d}, 2 \mathrm{H}, J=8.26 \mathrm{~Hz}\right.$, phenyl, $\left.\mathrm{C}_{3,5}-\mathrm{H}\right), 7.41(\mathrm{~d}, 2 \mathrm{H}, J=8.24 \mathrm{~Hz}$, phenyl, $\left.\mathrm{C}_{2,6}-\mathrm{H}\right), 10.01$ (s, $\left.1 \mathrm{H},-\mathrm{NHCO}\right)$. MS (ESI) $(\mathrm{m} / z)$ : [M $+1]^{+}$407.16. Anal. Calcd. for $\mathrm{C}_{20} \mathrm{H}_{30} \mathrm{~N}_{4} \mathrm{OS}_{2}$ : C, 59.08; H, 7.44; N, 13.78; Found: C, 59.22; H, 7.46; N, 13.71 .

2.5.18. N-[4-(4-Methylpiperazin-1-yl)phenyl]-2-(4-benzylpiperidin-1-yl-thiocarbonylthio)acetamide (4s). IR (KBr) $\nu_{\max }$ $\left(\mathrm{cm}^{-1}\right)$ : $3275(\mathrm{~N}-\mathrm{H}), 1659(\mathrm{C}=\mathrm{O}), 1221(\mathrm{C}=\mathrm{S}), 822(1,4-$ disubstituted benzene). ${ }^{1} \mathrm{H}-\mathrm{NMR}$ (500 MHz, DMSO-d6): 1.51-1.62 (m, 5H, piperidine, $\left.\mathrm{C}_{3,4,5}-\mathrm{H}\right), 2.61(\mathrm{~d}, 2 \mathrm{H}, \mathrm{J}=$ $\left.7.16 \mathrm{~Hz},-\mathrm{CH}_{2} \mathrm{C}_{6} \mathrm{H}_{5}\right), 3.05-3.09\left(\mathrm{~m}, 4 \mathrm{H}\right.$, piperidine, $\mathrm{C}_{2,6}{ }^{-}$ $\mathrm{H}), 3.44-3.75\left(\mathrm{~m}, 8 \mathrm{H}\right.$, piperazine, $\left.\mathrm{C}_{2,3,5,6}-\mathrm{H}\right), 4.18(\mathrm{~s}, 2 \mathrm{H}$, $\left.\mathrm{COCH}_{2}\right), 6.88\left(\mathrm{~d}, 2 \mathrm{H}, \mathrm{J}=8.11 \mathrm{~Hz}\right.$, phenyl, $\left.\mathrm{C}_{3,5}-\mathrm{H}\right), 7.17-7.30$ (m, 5H, $\left.-\mathrm{CH}_{2} \underline{\mathrm{C}}_{6} \underline{\mathrm{H}}_{5}\right), 7.42\left(\mathrm{~d}, 2 \mathrm{H}, \mathrm{J}=8.27 \mathrm{~Hz}\right.$, phenyl, $\mathrm{C}_{2,6}{ }^{-}$ $\mathrm{H}), 10.04$ (s, $1 \mathrm{H}, \mathrm{NHCO})$. MS (ESI) $(\mathrm{m} / z)$ : $[\mathrm{M}+1]^{+} 483.15$. Anal. Calcd. for $\mathrm{C}_{26} \mathrm{H}_{34} \mathrm{~N}_{4} \mathrm{OS}_{2}$ : C, 64.69; H, 7.10; N, 11.61; Found: C, 64.77; H, 7.12; N, 11.58.

2.6. Enzymatic Assay. All compounds were subjected to a slightly modified method of Ellman's test $[30,31]$ in order to evaluate their potency to inhibit the AChE. Donepezil hydrochloride was used as a positive control (Table 2). Enzyme solutions were prepared in gelatin solution (1\%), at a concentration of 2.5 units $/ \mathrm{mL}$. AChE and compound solution $(50 \mu \mathrm{L})$ which is prepared in $2 \%$ DMSO at 0.1 and $1 \mathrm{mM}$ concentrations were added to $3.0 \mathrm{~mL}$ phosphate buffer $(\mathrm{pH} 8 \pm 0.1)$ and incubated at $25^{\circ} \mathrm{C}$ for $5 \mathrm{~min}$. The reaction was started by adding DTNB $(50 \mu \mathrm{L})$ and ATC $(10 \mu \mathrm{L})$ to the enzyme-inhibitor mixture. The production of the yellow anion was recorded for $10 \mathrm{~min}$ at $412 \mathrm{~nm}$. As a control, an identical solution of the enzyme without the inhibitor is processed following the same protocol. The blank reading contained $3.0 \mathrm{~mL}$ buffer, $50 \mu \mathrm{L} 2 \%$ DMSO, $50 \mu \mathrm{L}$ DTNB, and $10 \mu \mathrm{L}$ substrate. All processes were assayed in triplicate. The inhibition rate (\%) was calculated by the following equation:

$$
\text { Inhibition } \%=\frac{\left[\left(A_{C}-A_{B}\right)-\left(A_{I}-A_{B}\right)\right]}{\left(A_{C}-A_{B}\right)} \times 100,
$$

where $A_{I}$ is the absorbance in the presence of the inhibitor, $A_{C}$ is the absorbance of the control, and $A_{B}$ is the absorbance of blank reading. Both of the values are corrected with blank-reading value. SPSS for Windows 15.0 was used for
TABLE 2: \% Inhibition potency of the compounds on AChE at $10^{-3}$ $10^{-4} \mathrm{M}$ concentrations.

\begin{tabular}{lcc}
\hline Comp. & \multicolumn{2}{c}{ Inhibition $\%$} \\
\hline $\mathbf{4 a}$ & $10^{-3} \mathrm{M}$ & $10^{-4} \mathrm{M}$ \\
$\mathbf{4 b}$ & 16.95 & 16.45 \\
$\mathbf{4 c}$ & 16.21 & 14.36 \\
$\mathbf{4 d}$ & 41.93 & 12.98 \\
$\mathbf{4 e}$ & 31.39 & 9.78 \\
$\mathbf{4 f}$ & 41.48 & 11.47 \\
$\mathbf{4 g}$ & 9.54 & 8.37 \\
$\mathbf{4 h}$ & 7.56 & 2.42 \\
$\mathbf{4 i}$ & 8.58 & 1.97 \\
$\mathbf{4 j}$ & 15.56 & 1.02 \\
$\mathbf{4 k}$ & 15.55 & 1.49 \\
$\mathbf{4 1}$ & 12.11 & 3.01 \\
$\mathbf{4 m}$ & 6.31 & 3.86 \\
$\mathbf{4 n}$ & 9.47 & 2.43 \\
$\mathbf{4 o}$ & 12.11 & 2.17 \\
$\mathbf{4 p}$ & 28.81 & 9.31 \\
$\mathbf{4 r}$ & 37.78 & 2.36 \\
$\mathbf{4 s}$ & 7.65 & 7.43 \\
$\mathbf{D o n e p e z i l}$ & 7.40 & 5.10 \\
\hline
\end{tabular}

statistical analysis. Student's $t$-test was used for all statistical calculations. Data were expressed as mean \pm SD inactive in culture medium.

2.7. Broth Microdilution Assay. The antimicrobial activities of compounds were tested using the microbroth dilution method [32]. MIC readings were performed twice for each chemical agent. Final products were tested for their in vitro growth inhibitory activity against Enterococcus faecalis (ATCC 29212), Pseudomonas aeruginosa (ATCC 27853), Klebsiella pneumoniae (ATCC 700603), Escherichia coli (ATCC 35218), Escherichia coli (ATCC 25923), Candida albicans (ATCC 10231), Candida glabrata (ATCC 90030), Candida krusei (ATCC 6258), and Candida parapsilosis (ATCC 7330). Chloramphenicol and ketoconazole were used as control drugs.

The cultures were obtained from Mueller-Hinton broth (Difco) for the bacterial strains after overnight incubation at $35 \pm 1^{\circ} \mathrm{C}$. The yeasts were maintained in Sabouraud dextrose broth (Difco) after overnight incubation $35 \pm 1^{\circ} \mathrm{C}$. The inocula of test microorganisms were adjusted to match the turbidity of a MacFarland 0.5 standard tube as determined with a spectrophotometer and the final inoculum size was 0.5-2.5 $\times 10^{5} \mathrm{cfu} / \mathrm{mL}$ for antibacterial and antifungal assays. Testing was carried out in Mueller-Hinton broth and Sabouraud dextrose broth (Difco) at $\mathrm{pH} 7$ and the twofold serial dilution technique was applied. The last well on the microplates containing only inoculated broth was kept as controls and the last well with no growth of microorganism was recorded to represent the MIC expressed in $\mu \mathrm{g} / \mathrm{mL}$. For both the antibacterial and antifungal assays the compounds were 
TABLE 3: Antimicrobial activities of the compounds as MIC values $(\mu \mathrm{g} / \mathrm{mL})$.

\begin{tabular}{|c|c|c|c|c|c|c|c|c|c|}
\hline Comp. & $\mathrm{A}$ & B & $\mathrm{C}$ & $\mathrm{D}$ & $\mathrm{E}$ & $\mathrm{F}$ & $\mathrm{G}$ & $\mathrm{H}$ & I \\
\hline $4 a$ & 25 & 50 & $25^{*}$ & $25^{*}$ & $25^{*}$ & $25^{* *}$ & $25^{* *}$ & $25^{* *}$ & $25^{* *}$ \\
\hline $4 b$ & 200 & 50 & 50 & 50 & 200 & $50^{*}$ & $25^{* *}$ & $50^{*}$ & $50^{*}$ \\
\hline $4 c$ & 25 & 50 & 50 & 50 & 50 & $50^{*}$ & $50^{*}$ & $25^{* *}$ & $50^{*}$ \\
\hline 4d & 200 & 50 & 50 & 50 & 200 & $50^{*}$ & $50^{*}$ & $50^{*}$ & $25^{* *}$ \\
\hline $4 e$ & 50 & 50 & $25^{*}$ & $25^{*}$ & 50 & $25^{* *}$ & $50^{*}$ & $25^{* *}$ & $50^{*}$ \\
\hline $4 f$ & 25 & 50 & 50 & 50 & 50 & $50^{*}$ & $50^{*}$ & $50^{*}$ & $50^{*}$ \\
\hline $4 g$ & 200 & 200 & 200 & 200 & 200 & $50^{*}$ & $50^{*}$ & $50^{*}$ & 200 \\
\hline $4 h$ & 50 & 50 & 50 & 50 & 200 & 200 & 100 & 400 & 400 \\
\hline $4 i$ & 200 & 200 & 200 & 200 & 200 & 400 & $50^{*}$ & 400 & 400 \\
\hline $4 j$ & 200 & 200 & 200 & 200 & 200 & 400 & $50^{*}$ & 400 & 400 \\
\hline $4 k$ & 200 & 50 & 50 & 50 & 200 & 400 & $50^{*}$ & 400 & 400 \\
\hline 41 & 200 & 200 & 50 & 50 & 200 & 400 & $50^{*}$ & 400 & 200 \\
\hline $4 \mathrm{~m}$ & 200 & 50 & 50 & 50 & 200 & 400 & $50^{*}$ & $50^{*}$ & 200 \\
\hline $4 n$ & 200 & 200 & 50 & 50 & 50 & 400 & $50^{*}$ & $50^{*}$ & 200 \\
\hline 40 & 200 & 50 & 50 & 50 & 200 & 400 & $50^{*}$ & $50^{*}$ & 200 \\
\hline $4 p$ & 200 & 200 & $25^{*}$ & $25^{*}$ & 200 & 400 & $50^{*}$ & 200 & 200 \\
\hline $4 r$ & 50 & 50 & 50 & 50 & 50 & 400 & $50^{*}$ & 400 & $50^{*}$ \\
\hline $4 s$ & 200 & 200 & 50 & 50 & 200 & 400 & 100 & 200 & 400 \\
\hline Ref-1 & 6.125 & 25 & 25 & 25 & 25 & - & - & - & - \\
\hline Ref-2 & - & - & - & - & - & 50 & 50 & 50 & 50 \\
\hline
\end{tabular}

A: Enterococcus faecalis (ATCC 29212), B: Pseudomonas aeruginosa (ATCC 27853), C: Klebsiella pneumoniae (ATCC 700603), D: Escherichia coli (ATCC 35218), E: Escherichia coli (ATCC 25923), F: Candida albicans (ATCC 10231), G: Candida glabrata (ATCC 90030), H: Candida krusei (ATCC 6258), and I: Candida parapsilosis (ATCC 7330). Ref-1: chloramphenicol, Ref-2: ketoconazole. ${ }^{*}$ Equal activity to reference. ${ }^{* *}$ Better activity than reference.

dissolved in DMSO. Further dilutions of the compounds and standard drugs in test medium were prepared at the required quantities of $800,400,200,100,50,25,12.5,6.25,3.13$, and $1.63 \mu \mathrm{g} / \mathrm{mL}$ concentrations with Mueller-Hinton broth and Sabouraud dextrose broth $[32,33]$. Each experiment in the antimicrobial assays was replicated twice in order to define the MIC values given in Table 1.

\section{Results and Discussion}

In the present study some $\mathrm{N}$-[(4-substituted-phenyl)-2substitutedthiocarbonylthio] acetamide derivatives (4a-4s) were synthesized in order to evaluate their biological activities. Target compounds were prepared in four steps. Initially, 4-fluoro-1-nitrobenzene in DMF was reacted with appropriate cyclic secondary amine under microwave irradiation to obtain 4-substituted-1-nitrobenzene derivatives (1a-1c). In the second step, nitro group reduction of $\mathbf{1 a}-\mathbf{1 c}$ gave 4substituted aniline derivatives $(\mathbf{2 a}-\mathbf{2} \mathbf{c})$, which were acetylated in further step by chloroacetyl chloride to gain 2chloro-N-(4-substituted-phenyl)acetamides (3a-3c). Finally, compounds $3 \mathbf{a}-\mathbf{3} \mathbf{c}$ were reacted with appropriate dithiocarbamic acid sodium salt to obtain target compounds (4a-4s). Synthetic route for the preparation of target compounds is outlined in Scheme 1. Some physicochemical properties of the compounds are given in Table 1 .

Structure elucidations of the final compounds $(\mathbf{4 a}-\mathbf{4 s})$ were performed with IR, ${ }^{1} \mathrm{H}$-NMR, and ES-MS spectroscopic methods and elemental analysis. Characteristic stretching absorptions of $\mathrm{C}=\mathrm{O}$ groups and $\mathrm{N}-\mathrm{H}$ bonds were observed at $1651-1661 \mathrm{~cm}^{-1}$ and $3273-3493 \mathrm{~cm}^{-1}$, respectively. The stretching absorptions at about $1230 \mathrm{~cm}^{-1}$ were assigned to $\mathrm{C}=\mathrm{S}$ bond. In the ${ }^{1} \mathrm{H}$-NMR spectra, all of the aromatic and aliphatic protons were observed at the estimated chemical shifts. The N-H proton of the acetylamino group gave a singlet signal at $9.99-10.06 \mathrm{ppm}$. The aromatic protons of 1,4-disubstituted phenyl ring were found at $6.87-7.45 \mathrm{ppm}$. The $-\mathrm{COCH}_{2}$ protons appeared as singlet signals at 4.17$4.21 \mathrm{ppm}$. The $\mathrm{M}+1$ peaks in ES-MS spectra were in agreement with the calculated molecular weight of the target compounds $(\mathbf{4 a}-\mathbf{4 s})$. Elemental analysis results for $\mathrm{C}, \mathrm{H}$, and $\mathrm{N}$ elements were satisfactory within $0.4 \%$ calculated values of the compounds.

The anticholinesterase effects of the compounds $(4 a-$ 4s) were determined by modified Ellman's spectrophotometric method (Table 2). Donepezil was used as a standard AChE inhibitor. The tested compounds showed low enzyme inhibitory activity. However, the compounds $\mathbf{4 c}$ and $\mathbf{4 e}$, which carry piperidine ring on fourth position of phenyl, displayed better inhibitory activity than other compounds.

Contrary to their enzyme inhibitory potency synthesized compounds displayed good antimicrobialy activity profile. Antibacterial activity of the compounds $4 a, 4 e$, and $4 \mathbf{p}$ (MIC $=25 \mu \mathrm{g} / \mathrm{mL}$ ) was equal to that of chloramphenicol against Klebsiella pneumoniae (ATCC 700603) and Escherichia coli (ATCC 35218). Most of the compounds (4b-4d, $\mathbf{4 f}, \mathbf{4 h}, \mathbf{4 k}-$ 4o, 4r, and $4 \mathbf{s}$ ) showed moderate antibacterial activity against these two bacterial strains (Table 3). 


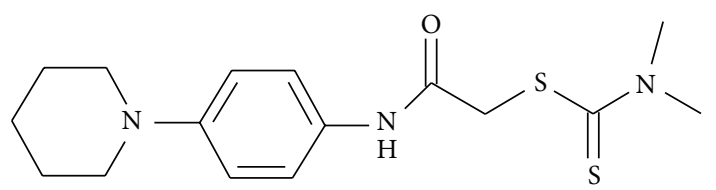

FIgURE 2: Chemical structure of compound 4a.

When compared with bacterial strain, Candida species were found to be more sensitive to synthesized compounds. Compound 4a (Figure 2) which carries piperidin-1-yl substituent and dimethylthiocarbamoyl side chain as variable groups exhibited twofold better anticandidal effect than reference drug ketoconazole. Furthermore, the other piperidin1-yl substituted compounds $\mathbf{4 b} \mathbf{- 4 f}$ showed significant antifungal activity (Table 3). Although morpholin-4-yl and 4methylpiperazin-1-yl substituted compounds $\mathbf{4 g - 4 1}$ and $\mathbf{4 m -}$ 4s showed equal activity to reference drug against Candida glabrata (ATCC 90030), their potency against the other Candida species was not the same with reference. This finding suggests that piperidin-1-yl substitution has good influence on antifungal activity. Besides, dimethylthiocarbamoyl side chain raises the antifungal activity significantly.

\section{Conclusion}

In an effort to develop potent anticholinesterase and antimicrobial agents, we described the synthesis of a series of N-[(4-substituted-phenyl)-2-substitutedthiocarbonylthio] acetamide derivatives (4a-4s) and focused on their biological activity evaluation. Anticholinesterase activity of the synthesized compounds was not as notable as antimicrobial activity. When compared with antibacterial activity, target compounds displayed better antifungal effect profile. Among these derivatives, compound $\mathbf{4 a}$ can be identified as the most promising antifungal agent against all tested Candida species with a twofold lower MIC value $(25 \mu \mathrm{g} / \mathrm{mL})$ than ketoconazole. This result may have a good impact on medicinal chemists to synthesize more active compounds that contain similar chemical structure.

\section{Conflict of Interests}

The authors declare that there is no conflict of interests regarding the publication of this paper.

\section{Acknowledgment}

This study was financially supported by Anadolu University Scientific Research Projects Fund, project no. 1205 S88.

\section{References}

[1] W. Thies and L. Bleiler, "2012 Alzheimer's disease facts and figures," Alzheimer's and Dementia, vol. 8, no. 2, pp. 131-168, 2012.

[2] V. Zarotsky, J. J. Sramek, and N. R. Cutler, "Galantamine hydrobromide: an agent for Alzheimer's disease," American
Journal of Health-System Pharmacy, vol. 60, no. 5, pp. 446-452, 2003.

[3] J. A. Schneider, Z. Arvanitakis, W. Bang, and D. A. Bennett, "Mixed brain pathologies account for most dementia cases in community-dwelling older persons," Neurology, vol. 69, no. 24, pp. 2197-2204, 2007.

[4] A. C. Tricco, S. Vandervaart, C. Soobiah et al., "Efficacy of cognitive enhancers for Alzheimer's disease: protocol for a systematic review and network meta-analysis," Systematic Reviews, vol. 1, no. 1, article 31, 2012.

[5] N. Perry, G. Court, N. Bidet, J. Court, and E. Perry, "European herbs with cholinergic activities: potential in dementia therapy," International Journal of Geriatric Psychiatry, vol. 11, pp. 10631069, 1996.

[6] C. I. Wright, C. Geula, and M.-M. Mesulam, "Neuroglial cholinesterases in the normal brain and in Alzheimer's disease: relationship to plaques, tangles, and patterns of selective vulnerability," Annals of Neurology, vol. 34, no. 3, pp. 373-384, 1993.

[7] S. E. Arnold and A. Kumar, "Reversible dementias," Medical Clinics of North America, vol. 77, pp. 215-225, 1993.

[8] M. Adams, F. Gmünder, and M. Hamburger, "Plants traditionally used in age related brain disorders-a survey of ethnobotanical literature," Journal of Ethnopharmacology, vol. 113, no. 3, pp. 363-381, 2007.

[9] J. Takahashi, I. Hijikuro, T. Kihara et al., "Design, synthesis and evaluation of carbamate-modified (-)- $N^{1}$-phenethylnorphysostigmine derivatives as selective butyrylcholinesterase inhibitors," Bioorganic \& Medicinal Chemistry Letters, vol. 20, no. 5, pp. 1721-1723, 2010.

[10] C. N. Lieske, R. T. Gepp, J. H. Clark, H. G. Meyer, P. Blumbergs, and C. C. Tseng, "Anticholinesterase activity of potential therapeutic 5-(1,3, 3-trimethylindolinyl) carbamates," Journal of Enzyme Inhibition, vol. 5, no. 3, pp. 215-223, 1991.

[11] P. M. Madalageri and O. Kotresh, "Synthesis, DNA protection and antimicrobial activity of some novel chloromethyl benzimidazole derivatives bearing dithiocarbamates," Journal of Chemical and Pharmaceutical Research, vol. 4, no. 5, pp. 26972703, 2012.

[12] R. B. Silverman, The Organic Chemistry of Drug Design and Drug Action, Chapter 2, Elsevier Academic Press, Burlington, Vt, USA, 2004.

[13] H. Waterbeemd and R. Mannhold, Lipophilicity descriptors for structure-property orrelation studies: overview of experimental and theoretical methods and a benchmark of $\log P$ calculations. Lipophilicity in Drug Action and Toxicology, chapter 23, VCH Publishers, NewYork, NY, USA, 1996.

[14] R. Tokuyama, Y. Takahashi, Y. Tomita et al., "Structureactivity relationship (SAR) studies on oxazolidinone antibacterial agents. 2.1) Relationship between lipophilicity and antibacterial activity in 5-thiocarbonyl oxazolidinones," Chemical and Pharmaceutical Bulletin, vol. 49, no. 4, pp. 353-360, 2001.

[15] G. A. Patani and E. J. LaVoie, "Bioisosterism: a rational approach in drug design," Chemical Reviews, vol. 96, no. 8, pp. 3147-3176, 1996.

[16] X.-J. Wang, H.-W. Xu, L.-L. Guo et al., "Synthesis and in vitro antitumor activity of new butenolide-containing dithiocarbamates," Bioorganic and Medicinal Chemistry Letters, vol. 21, no. 10, pp. 3074-3077, 2011.

[17] K. Bacharaju, S. R. Jambula, S. Sivan, S. Jyostnatangeda, and V. Manga, "Design, synthesis, molecular docking and biological evaluation of new dithiocarbamates substituted benzimidazole 
and chalcones as possible chemotherapeutic agents," Bioorganic \& Medicinal Chemistry Letters, vol. 22, no. 9, pp. 3274-3277, 2012.

[18] G. Turan-Zitouni, A. Özdemir, and K. Güven, "Synthesis of some 1-[(N,N-disubstituted thiocarbamoylthio)acetyl $]-3-(2-$ thienyl)-5-aryl-2-pyrazoline derivatives and investigation of their antibacterial and antifungal activities," Archiv der Pharmazie, vol. 338, no. 2-3, pp. 96-104, 2005.

[19] P. Vicini, A. Geronikaki, K. Anastasia, M. Incerti, and F. Zani, "Synthesis and antimicrobial activity of novel 2thiazolylimino-5-arylidene-4-thiazolidinones," Bioorganic and Medicinal Chemistry, vol. 14, no. 11, pp. 3859-3864, 2006.

[20] K. H. Chikhalia, D. B. Vashi, and M. J. Patel, "Synthesis of a novel class of some 1,3,4-oxadiazole derivatives as antimicrobial agents," Journal of Enzyme Inhibition and Medicinal Chemistry, vol. 24, no. 3, pp. 617-622, 2009.

[21] C. R. Miller and W. O. Elson, "Dithiocarbamic acid derivatives; the relation of chemical structure to in vitro antibacterial and antifungal activity against human pathogens," Journal of Bacteriology, vol. 57, no. 1, pp. 47-54, 1949.

[22] A. M. Kligman and W. Rosensweig, "Studies with new fungistatic agents for the treatment of superficial mycoses," The Journal of Investigative Dermatology, vol. 10, no. 2, pp. 59-68, 1948.

[23] A. C. Karaburun, Z. A. Kaplanciklı, N. Gundogdu-Karaburun, and F. Demirci, "Synthesis, antibacterial and antifungal activities of some carbazole dithiocarbamate derivatives," Letters in Drug Design \& Discovery, vol. 8, pp. 811-815, 2011.

[24] D. C. Hooper, "Mode of action of fluoroquinolones," Drugs, vol. 58, no. 2, pp. 6-10, 1999.

[25] E. Wyrzykiewicz, M. Wendzonka, and B. Kedzia, "Synthesis and antimicrobial activity of new (E)-4-[piperidino ( $4^{\prime}$ methylpiperidino-, morpholino-) N-alkoxy]stilbenes," European Journal of Medicinal Chemistry, vol. 41, no. 4, pp. 519-525, 2006.

[26] P. P. Dixit, P. S. Nair, V. J. Patil, S. Jain, S. K. Arora, and N. Sinha, "Synthesis and antibacterial activity of novel (un)substituted benzotriazolyl oxazolidinone derivatives," Bioorganic and Medicinal Chemistry Letters, vol. 15, no. 12, pp. 3002-3005, 2005.

[27] P. Panneerselvam, R. R. Nair, G. Vijayalakshmi, E. H. Subramanian, and S. K. Sridhar, "Synthesis of Schiff bases of 4-(4aminophenyl)-morpholine as potential antimicrobial agents," European Journal of Medicinal Chemistry, vol. 40, no. 2, pp. 225229, 2005.

[28] T. Elavarasan, D. P. Bhakiaraj, and M. Gopalakrishnan, "Synthesis, spectral analysis, in vitro microbiological evaluation, and molecular docking studies of some novel 1-(1-aryl-1H-tetrazol5-yl)-2-(piperidin-1-yl) ethanone derivatives," ISRN Organic Chemistry, vol. 2014, Article ID 120173, 9 pages, 2014.

[29] K. Paulrasu, A. Duraikannu, M. Palrasu, A. Shanmugasundaram, M. Kuppusamy, and B. Thirunavukkarasu, "Synthesis of 4-methyl- $N^{\prime}$-(3-alkyl-2r,6c-diarylpiperidin-4-ylidene)-1,2,3thiadiazole-5-carbohydrazides with antioxidant, antitumor and antimicrobial activities," Organic \& Biomolecular Chemistry, vol. 12, no. 31, pp. 5911-5921, 2014.

[30] G. L. Ellman, K. D. Courtney, V. Andres Jr., and R. M. Featherstone, "A new and rapid colorimetric determination of acetylcholinesterase activity," Biochemical Pharmacology, vol. 7, no. 2, pp. 88-95, 1961.
[31] N. S. L. Perry, P. J. Houghton, A. Theobald, P. Jenner, and E. K. Perry, "In-vitro inhibition of human erythrocyte acetylcholinesterase by Salvia lavandulaefolia essential oil and constituent terpenes," Journal of Pharmacy and Pharmacology, vol. 52, no. 7, pp. 895-902, 2000.

[32] W. Winn, S. Allen, W. Janda et al., In Color Atlas and Textbook of Diagnostic Microbiology, Lippincott Williams \& Wilkins, Baltimore, Md, USA, 6th edition, 2006.

[33] A. Espinel-Ingroff, "In vitro fungicidal activities of voriconazole, itraconazole, and amphotericin B against opportunistic moniliaceous and dematiaceous fungi," Journal of Clinical Microbiology, vol. 39, no. 3, pp. 954-958, 2001. 

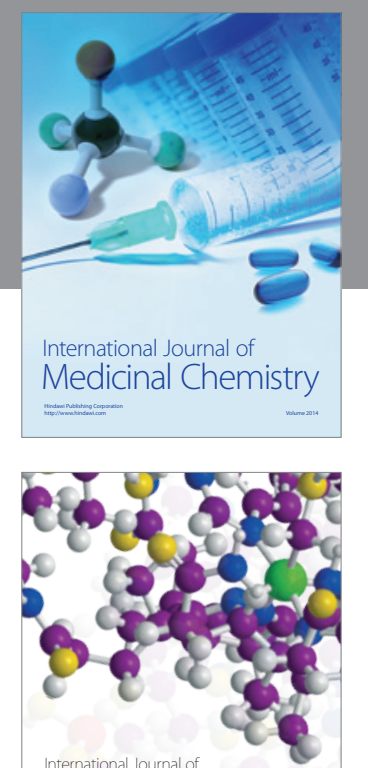

\section{Carbohydrate} Chemistry

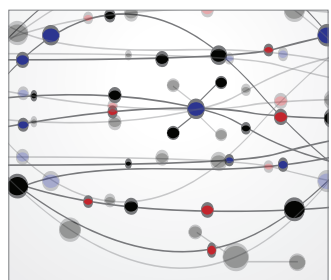

The Scientific World Journal
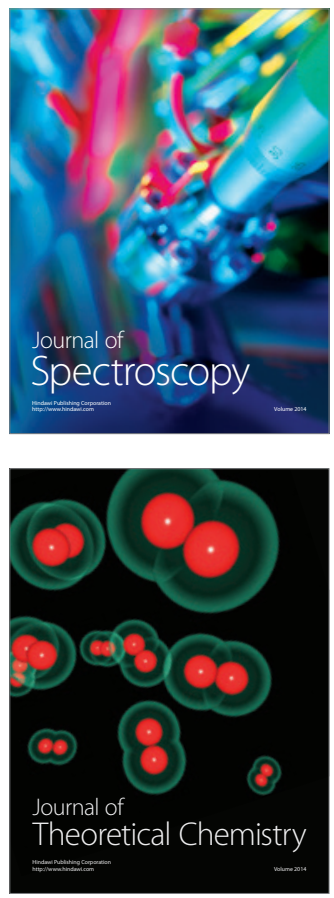
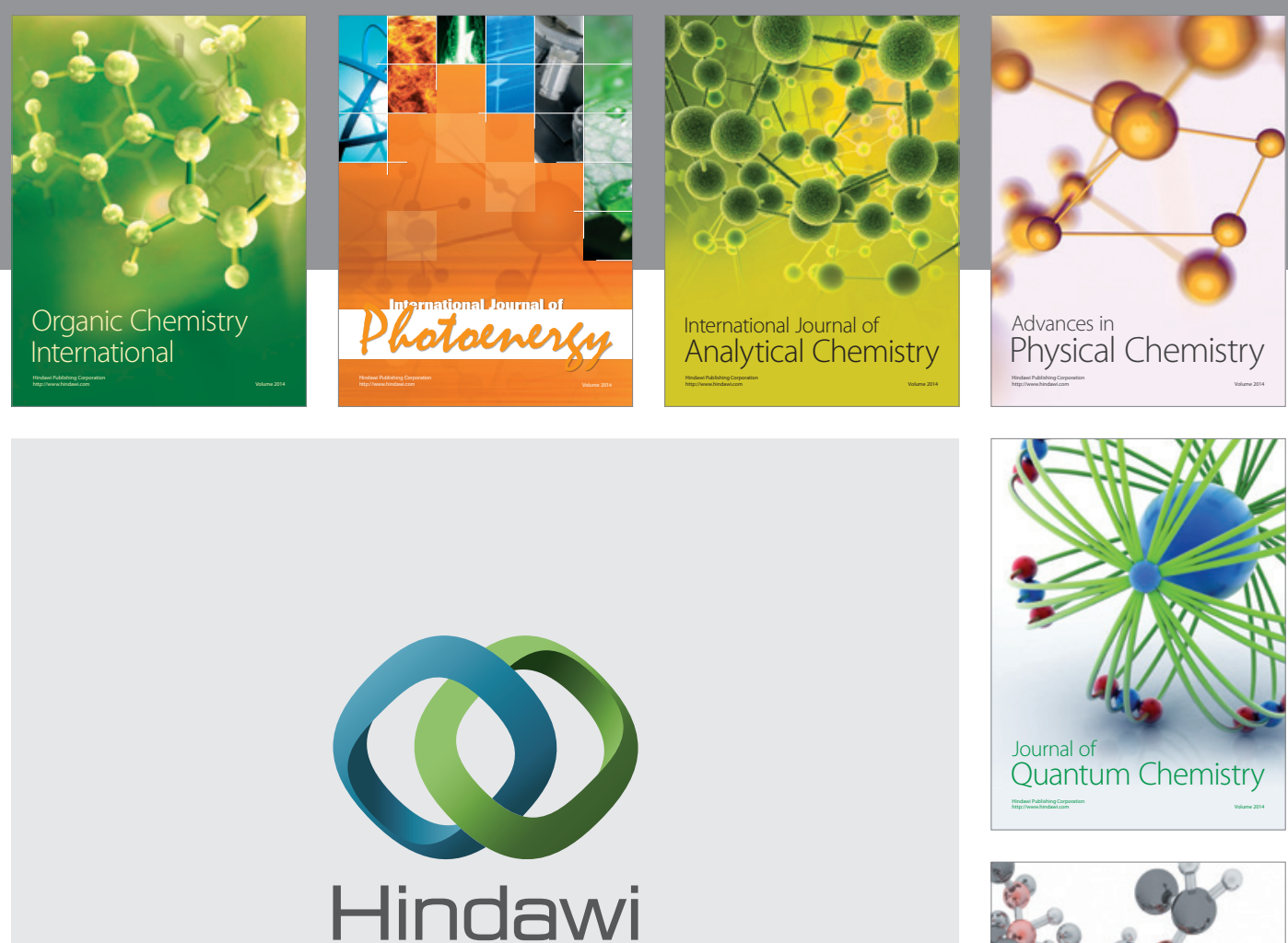

Submit your manuscripts at

http://www.hindawi.com

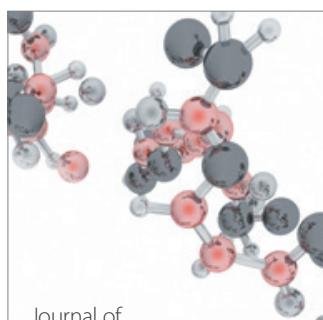

Analytical Methods

in Chemistry

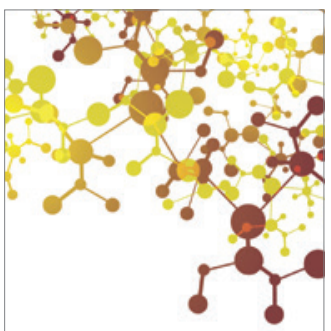

Journal of

Applied Chemistry

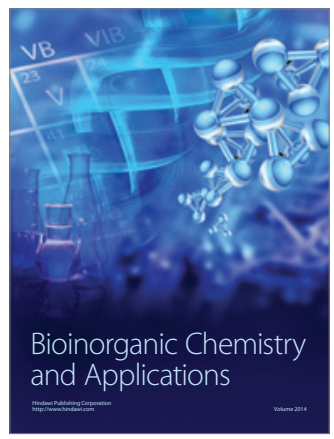

Inorganic Chemistry
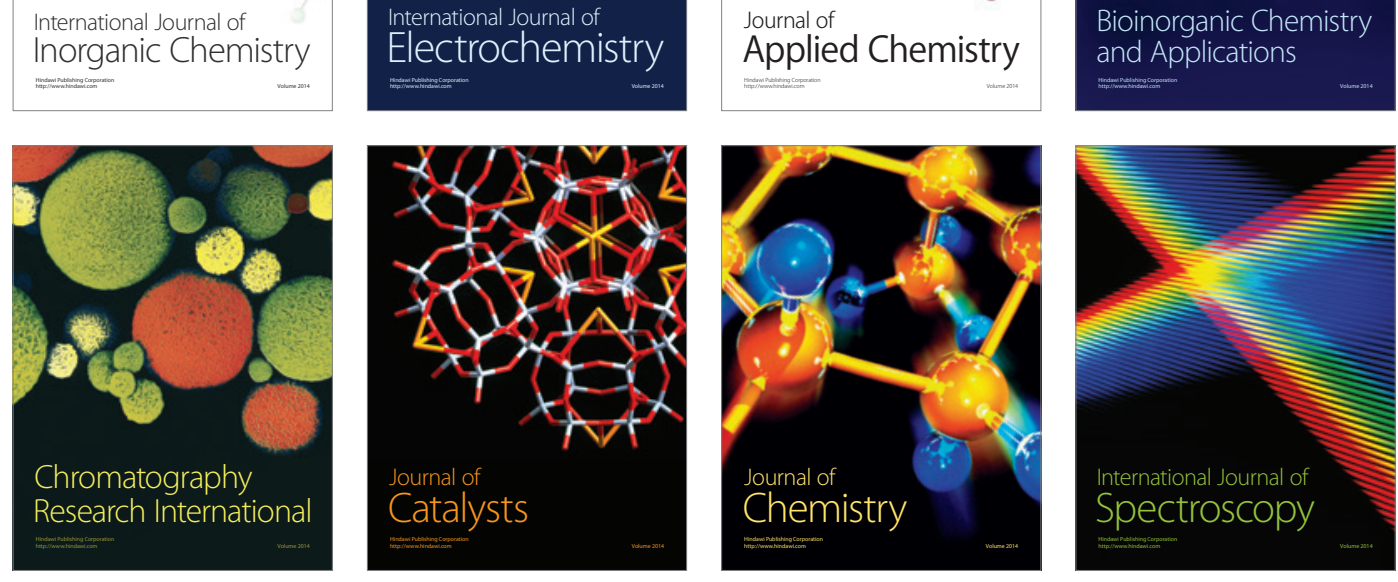